\title{
Correction to: Short-term outcomes in children recovered from multisystem inflammatory syndrome associated with SARS-CoV-2 infection
}

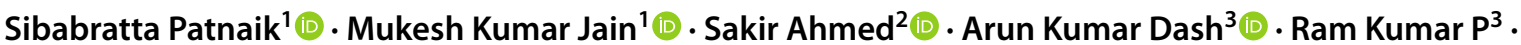 \\ Bandya Sahoo $^{3}$ (D) $\cdot$ Reshmi Mishra $^{3}$ (D) Manas Ranjan Behera ${ }^{1}$ (i)
}

Published online: 22 July 2021

(c) Springer-Verlag GmbH Germany, part of Springer Nature 2021

\section{Correction to: Rheumatology International https://doi.org/10.1007/s00296-021-04932-1}

In the original article published, the author inadvertently missed to provide the acknowledgement details. The correct details are given below:

Acknowledgements: We are thankful to Prof. Sanghamitra Pati, Director ICMR-RMRC, Bhubaneswar and Dr. Debdutta Bhattacharya, Scientist D, ICMR-RMRC Bhubaneswar for helping in COVID antibody estimation.

The original article can be found online at https://doi.org/10.1007/ s00296-021-04932-1.

Sibabratta Patnaik

drsbpatnaik45@gmail.com

Sakir Ahmed

sakir005@gmail.com

Ram Kumar P

ramu@gmail.com

Bandya Sahoo

bandyasahoo@gmail.com

Reshmi Mishra

docreshmis@gmail.com

Manas Ranjan Behera

drmanas73@yahoo.co.in

1 Department of Pediatrics, Kalinga Institute of Medical Sciences, Bhubaneswar, India

2 Department of Clinical Immunology and Rheumatology, Kalinga Institute of Medical Sciences, Bhubaneswar, India

3 Department of Pediatrics, Kalinga Institute of Medical Sciences, Bhubaneswar, India
Publisher's Note Springer Nature remains neutral with regard to jurisdictional claims in published maps and institutional affiliations. 